\title{
Proton Tolerance of SiGe Precision Voltage References for Extreme Temperature Range Electronics
}

\author{
Laleh Najafizadeh, Student Member, IEEE, Marco Bellini, Student Member, IEEE, \\ A. P. Gnana Prakash, Member, IEEE, Gustavo A. Espinel, John D. Cressler, Fellow, IEEE, \\ Paul W. Marshall, Senior Member, IEEE, and Cheryl J. Marshall, Member, IEEE
}

\begin{abstract}
A comprehensive investigation of the effects of proton irradiation on the performance of $\mathrm{SiGe} \mathrm{BiCMOS}$ precision voltage references intended for extreme environment operational conditions is presented. The voltage reference circuits were designed in two distinct $\mathrm{SiGe} \mathrm{BiCMOS} \mathrm{technology} \mathrm{platforms} \mathrm{(first} \mathrm{generation}$ $(50 \mathrm{GHz})$ and third generation $(200 \mathrm{GHz}))$ in order to investigate the effect of technology scaling. The circuits were irradiated at both room temperature and at $77 \mathrm{~K}$. Measurement results from the experiments indicate that the proton-induced changes in the SiGe bandgap references are minor, even down to cryogenic temperatures, clearly good news for the potential application of SiGe mixed-signal circuits in emerging extreme environments.
\end{abstract}

Index Terms-BiCMOS analog integrated circuits, heterojuction bipolar transistors, proton radiation effects.

\section{INTRODUCTION}

$\mathbf{P}$ RECISE voltage references find application in virtually all electronic circuits and systems, including analog-to-digital and digital-to-analog converters, and thus are key components for many space exploration applications (e.g., robotic missions to the lunar surface). In such cases, having electronic circuits that operate robustly under extreme environment conditions (e.g., under radiation exposure and over wide temperature ranges) can greatly improve robotic system performance and reliability by eliminating the need for shielded "warm boxes" and their consequent highly-centralized architectures (the current practice, for instance, on the Moon and Mars). For applications on the Moon, for instance, the ambient temperature under which electronic circuits are desired to function can range from $+120^{\circ} \mathrm{C}$ (in the sunshine) to $-230^{\circ} \mathrm{C}$ (in shadowed polar craters). At such extremely low temperatures, among all available IC technologies, SiGe heterojunction bipolar transistor (SiGe HBT) technology has emerged as a viable candidate [1]. It is well known that Si bipolar transistors do not

Manuscript received July 14, 2006; revised August 25, 2006. This work was supported by DTRA under the Radiation Hardened Microelectronics Program, NASA-GSFC under the NASA Electronic Parts and Packaging (NEPP) Program, the NASA ETDP SiGe Program, and the Georgia Electronic Design Center at Georgia Tech.

L. Najafizadeh, M. Bellini, A.P.G. Prakash, G.A. Espinel, and J.D. Cressler are with the School of Electrical and Computer Engineering, Georgia Institute of Technology, Atlanta, GA 30308 USA (e-mail: laleh@ece.gatech.edu).

P. W. Marshall is a consultant to NASA-GSFC, Greenbelt, MD 20771 USA.

C. J. Marshall is with NASA-GSFC, Greenbelt, MD 20771 USA.

Color versions of one or more of the figures in this paper are available online at http://ieeexplore.ieee.org.

Digital Object Identifier 10.1109/TNS.2006.885381 operate well at cryogenic temperatures [1] and the reliability of CMOS devices generally worsens with cooling, especially below $77 \mathrm{~K}$ [2]. From a radiation perspective, previous studies have confirmed the overall robustness of SiGe technologies to total ionizing dose [3], [4]

In this paper we present, for the first time, SiGe bandgap voltage references (BGRs) designed specifically for such emerging extreme environment applications. The degradation of precision reference circuits due to proton irradiation has been previously investigated in [5]-[8]. In [5]-[7], however, only Si BJT voltage references were investigated, and to date no studies on the effects of radiation on their wide-temperature-range behavior have been performed. The BGR circuits presented here employ both CMOS and SiGe HBT transistors, with the HBTs used in the core of the reference circuits. To investigate the effect of technology scaling on the performance of the circuits, the SiGe references studied in this paper were designed in two SiGe technologies: first- and third-generation $\mathrm{SiGe}$ technologies. One type of the $\mathrm{SiGe}$ circuits exploits an exponential curvature-compensation technique [9].

For radiation experiments, all of the samples were characterized before being irradiated with $63 \mathrm{MeV}$ protons. Three different radiation experiments were performed. In the first experiment, voltage references from the two SiGe technologies were irradiated at room temperature, while being operated under bias. For the second experiment, the references from the two SiGe technologies were irradiated cold while under bias, and for the third experiment, one reference from the third-generation SiGe technology was irradiated at room temperature with all pins grounded. We present, for the first time, results on the effects of proton irradiation on these precision $\mathrm{SiGe}$ references down to temperatures as low as $-263^{\circ} \mathrm{C}$.

\section{PRocess Technology}

The bandgap voltage references used for this study were implemented in both commercially-available first- and third-generation SiGe BiCMOS technologies. The first-generation SiGe technology (IBM SiGe 5AM) is a four-level metal process and features SiGe HBTs with an emitter width of $0.5 \mu \mathrm{m}$ and a unity gain cut-off frequency and maximum frequency of oscillation of $45 \mathrm{GHz}$ and $60 \mathrm{GHz}$, respectively, nMOS and pMOS transistors with a nominal $\mathrm{L}_{\mathrm{eff}}$ of $0.35 \mu \mathrm{m}$, as well as polysilicon and diffused resistors, and various capacitors. The response of first-generation $\mathrm{SiGe} \mathrm{HBTs}$ to proton irradiation has been reported previously [10]. 


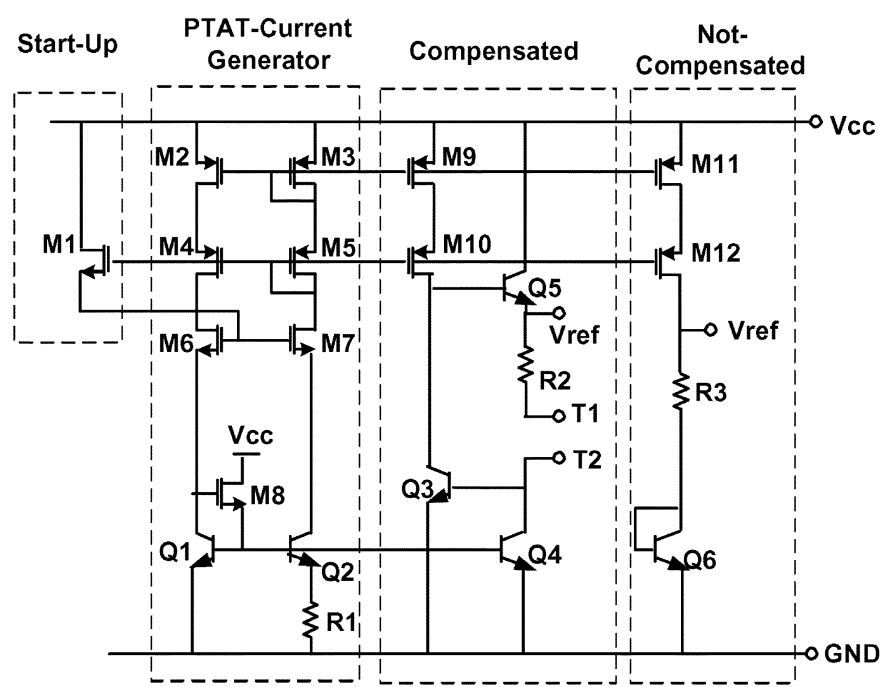

Fig. 1. Schematic of the $8 \mathrm{HP}$ SiGe bandgap references.

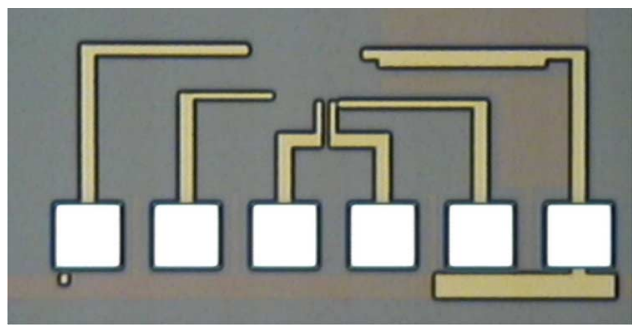

Fig. 2. Die micrograph of the $8 \mathrm{HP}$ SiGe bandgap references.

IBM's third-generation SiGe technology (IBM SiGe 8HP) employs a reduced thermal cycle, "raised extrinsic base" structure utilizing conventional deep and shallow trench isolation, an in-situ doped polysilicon emitter, and an unconditionally stable, $25 \%$ peak Ge, C-doped, graded UHV/CVD epitaxial SiGe base [11]. The device structure has been scaled laterally to $0.12 \mu \mathrm{m}$ emitter stripe width in order to minimize base resistance and improve the frequency response and broadband noise characteristics. Proton tolerance and the cryogenic performance of the SiGe HBTs in this technology have been previously reported in [4] and [12], respectively.

\section{Circuit Description}

The schematic of the voltage references implemented in 8HP technology is shown in Fig. 1. The circuit consists of two bandgap voltage references: an exponential curvature-compensated BGR [9] which exploits the temperature characteristics of the current gain of the SiGe HBT for curvature compensation, and a first-order (uncompensated) version [13]. The geometry of all of the SiGe HBTs, except for the $Q_{2}$, is $0.12 \times 5.0 \mu \mathrm{m}^{2}$. The area of transistor $Q_{2}$ consists of sixteen parallel copies of $Q_{1}$. Transistor $M_{1}$ is the startup circuit and transistors $M_{2}-M_{8}$ and $Q_{1}-Q_{2}$, along with the resistor $R_{1}$, generate the bias current for the various stages, which is proportional to the absolute temperature (PTAT). The third stage is designed to produce a curvature-compensated output voltage. Pads $T_{1}$ and $T_{2}$ are designed for external trimming (if required). The forth stage is simply a first-order bandgap reference, in which the

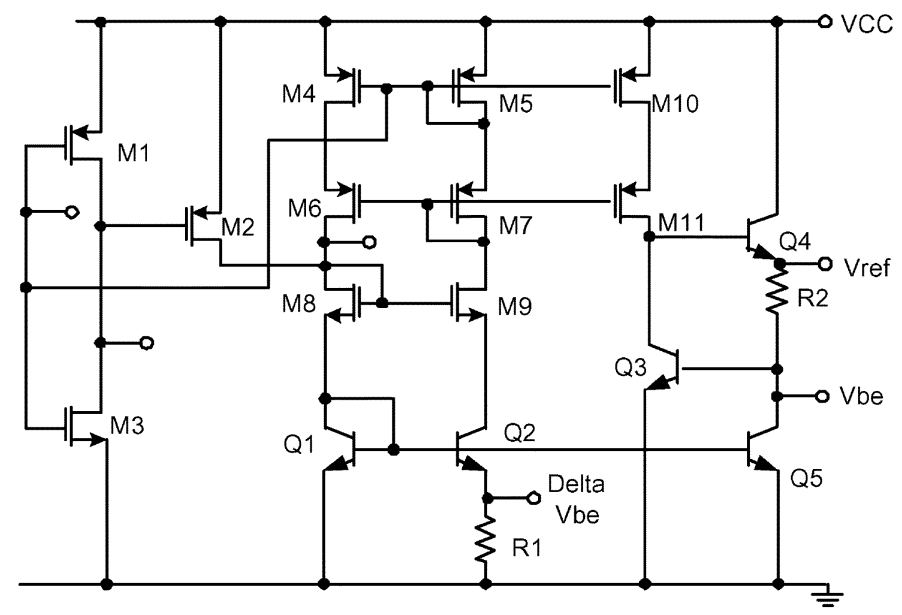

Fig. 3. Schematic of the $5 \mathrm{AM}$ SiGe bandgap reference.

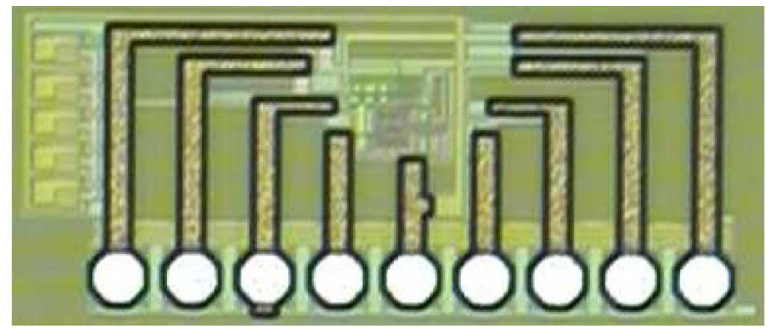

Fig. 4. Die micrograph of the 5AM SiGe bandgap reference.

negative temperature dependence of the base-emitter voltage of transistor $Q_{6}$ is canceled with the positive voltage generated by passing the PTAT current through the resistor $R_{3}$. Both circuits were designed for a power supply voltage of $2.5 \mathrm{~V}$. The circuit, including the pads, occupies $0.87 \times 0.43 \mathrm{~mm}^{2}$. The micrograph of the SiGe reference is shown in Fig. 2. Since the 8HP process is a seven metal layer technology, the circuit is not easily seen below the top layers.

In first-generation SiGe technology, only the curvature-compensated reference was implemented. The schematic is shown in Fig. 3. Each of the bipolar transistors shown in this figure, except for $Q_{2}$, consists of four parallel copies of the $0.5 \times 2.5 \mu \mathrm{m}^{2} \mathrm{SiGe}$ HBT. The area of transistor $Q_{2}$ is eight times larger than that of the other transistors. No pads were used for external trimming, while several pads have been inserted to monitor the nodes of individual transistors internal to the circuit. The circuit was designed for a power supply voltage of $3.3 \mathrm{~V}$. With the pads, the circuit occupies an area of $1.3 \times 0.4 \mathrm{~mm}^{2}$ (Fig. 4). In all cases, careful layout techniques were employed to reduce transistor mismatch effects.

\section{EXPERIMENT}

The major goal of this work was to carefully assess the impact of radiation exposure on precision voltage references operating down to very low temperatures. Such extreme conditions occur in many potential space exploration missions. Each circuit intended for test was mounted in a 28 pin ceramic DIP package, wire-bonded, and characterized before being sent for proton irradiation. The samples were irradiated with $63.3 \mathrm{MeV}$ protons 


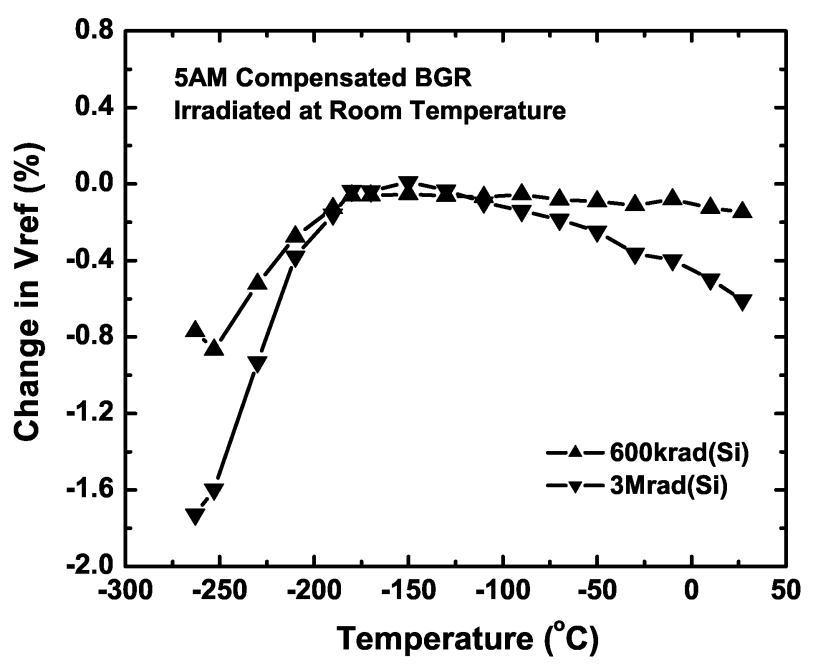

Fig. 5. Change in the output voltage of 5AM BGR irradiated at room temperature as a function of temperature.

at the Crocker Nuclear Laboratory at the University of California at Davis. The dosimetry measurements used a five-foil secondary emission monitor calibrated against a Faraday cup, and Ta scattering foils located several meters upstream of the target establish a beam spatial uniformity of $15 \%$ over a $2.0 \mathrm{~cm}$ radius circular area. The dosimetry system has been previously described [14], and is accurate to about $10 \%$. Three different experiments were performed as follows:

\section{A. Experiment I}

The circuits from both SiGe technologies, while being kept under operational bias, were irradiated at room temperature. Two different equivalent total doses were used: $600 \mathrm{krad}(\mathrm{Si})(\mathrm{a}$ proton fluence of $4.3 \times 10^{12} \mathrm{p} / \mathrm{cm}^{2}$ ) and $3 \mathrm{Mrad}(\mathrm{Si})$ (a proton fluence of $2.1 \times 10^{13} \mathrm{p} / \mathrm{cm}^{2}$ ).

\section{B. Experiment II}

The circuits from both $\mathrm{SiGe}$ technologies, while under bias, were inserted into a liquid nitrogen bath and were irradiated at $77 \mathrm{~K}$. The output voltages of the $8 \mathrm{HP}$ references were measured at $77 \mathrm{~K}$, during irradiation, at four total dose levels of $300 \mathrm{krad}(\mathrm{Si}), 600 \mathrm{krad}(\mathrm{Si}), 1 \mathrm{Mrad}(\mathrm{Si})$ and $3 \mathrm{Mrad}(\mathrm{Si})$. The measured equivalent total dose for the $5 \mathrm{AM}$ reference was $3 \mathrm{Mrad}(\mathrm{Si})$ (a proton fluence of $2.1 \times 10^{13} \mathrm{p} / \mathrm{cm}^{2}$ ).

\section{Experiment III}

The curvature-compensated circuit from the third-generation SiGe technology was irradiated at room temperature, with all terminals grounded (previously shown to have negligible impact on the radiation response of individual SiGe HBTs [15]). The measured equivalent total dose was $600 \mathrm{krad}(\mathrm{Si})$ (a proton fluence of $4.3 \times 10^{12} \mathrm{p} / \mathrm{cm}^{2}$ ).

\section{RESULTS AND DISCUSSION}

The output voltage of the circuits was measured before and after irradiation, at different temperatures ranging from $27^{\circ} \mathrm{C}$ down to $-263^{\circ} \mathrm{C}$. Electrical measurements were performed using an Agilent 4155 Semiconductor Parameter Analyzer.

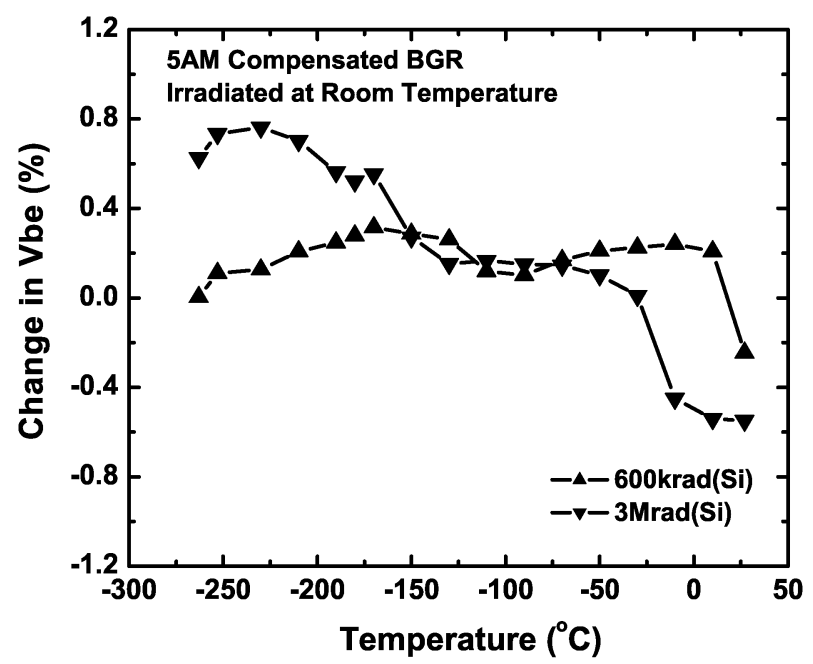

Fig. 6. Change in the base-emitter voltage of $Q_{3}$ inside 5AM BGR irradiated at room temperature as a function of temperature.

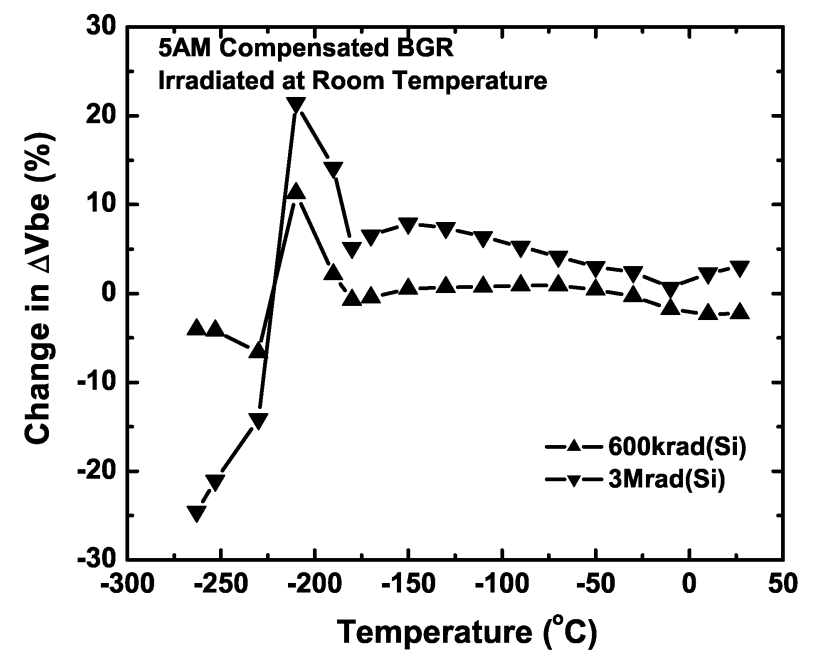

Fig. 7. Change in the difference of $Q_{1}$ and $Q_{2}$ base-emitter voltages of 5AM BGR irradiated at room temperature as a function of temperature.

In the following sections, the measurement results of each experiment are discussed.

\section{A. Experiment I}

Measurement results from Experiment I are shown in Figs. 5-11. As mentioned above, in this experiment the samples were irradiated at room temperature while they were under bias. Fig. 5 shows the percentage change in the output voltage of the 5AM BGR as a function of temperature for total dose values of $600 \mathrm{krad}(\mathrm{Si})$ and $3 \mathrm{Mrad}(\mathrm{Si})$. Previous studies on the effects of radiation on precision voltage references usually report this percentage change as a function of total dose/proton fluence, but only at room temperature. Here, we have shown these changes down to extremely low temperatures. The percentage change was calculated according to

$\Delta \operatorname{Vref}(\mathrm{T})(\%)=\frac{\operatorname{Vref}_{\text {post }-\operatorname{rad}}(\mathrm{T})-\operatorname{Vref}_{\text {pre-rad }}(\mathrm{T})}{\operatorname{Vref}_{\text {pre-rad }}(\mathrm{T})}$ $\times 100$. 


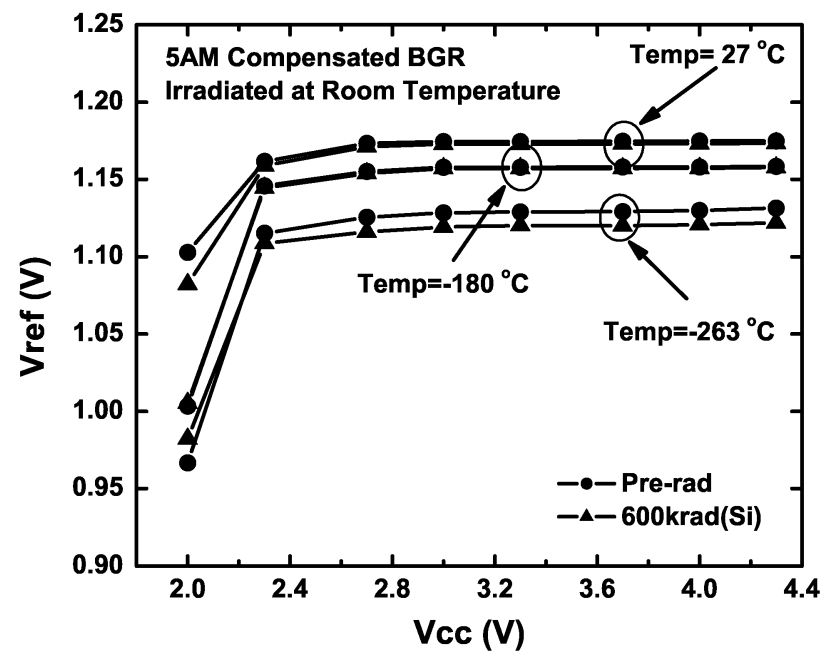

Fig. 8. Output voltage of the 5AM BGR irradiated at room temperature and total dose of $600 \mathrm{krad}(\mathrm{Si})$ as a function of power supply at $27^{\circ} \mathrm{C},-180^{\circ} \mathrm{C}$ and $-263^{\circ} \mathrm{C}$.

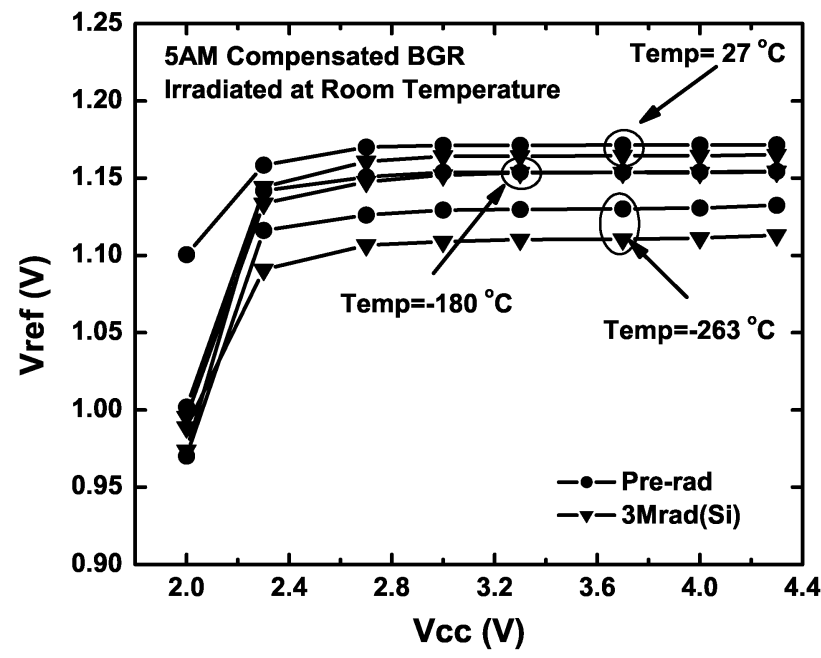

Fig. 9. Output voltage of the 5AM BGR irradiated at room temperature and total dose of $3 \mathrm{Mrad}(\mathrm{Si})$ as a function of power supply at $27^{\circ} \mathrm{C},-180^{\circ} \mathrm{C}$ and $-263^{\circ} \mathrm{C}$

As can be seen, for the case of $3 \mathrm{Mrad}(\mathrm{Si})$ total dose, the percentage change in the output voltage of 5AM BGR is larger than for the case of $600 \mathrm{krad}(\mathrm{Si})$, and the percentage change becomes larger at very low temperatures. To assess what part of circuit plays the role in causing the value of the output voltage to change after the reference was irradiated, the base-emitter voltage of transistor $Q_{3}$ and the base-emitter voltage difference of transistors $Q_{1}$ and $Q_{2}$ were measured both before and after irradiation and their percentage changes have been plotted in Figs. 6 and 7, respectively. One can see that the percentage change in the base-emitter voltage difference is much larger than the percentage change in the base-emitter voltage, indicating that the PTAT current generator likely plays the main role in causing the output voltage to change following irradiation. For this PTAT current generator section to operate properly, the current in the two branches should remain equal. Any mismatches between the large and small area transistors in these

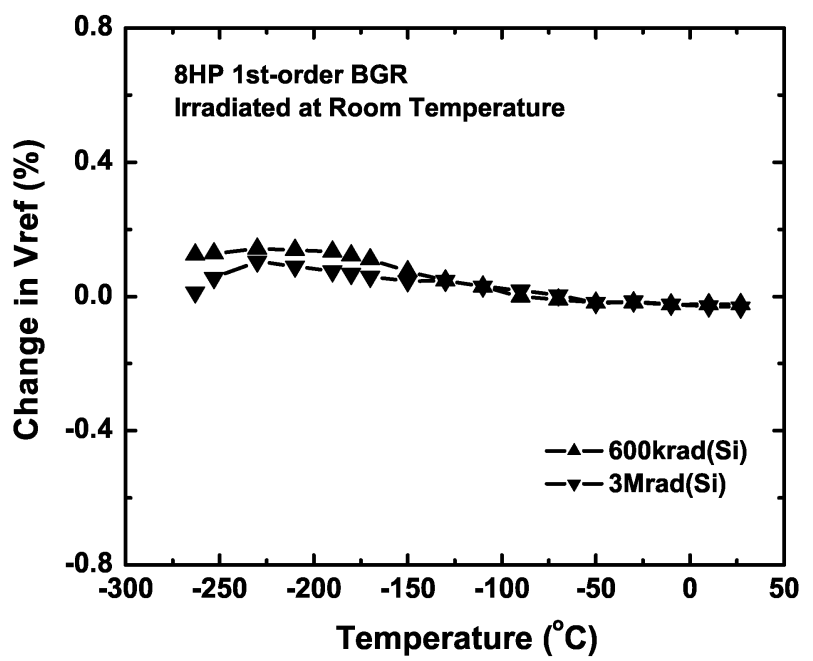

Fig. 10. Change in the output voltage of 1st-order 8HP BGR irradiated at room temperature as a function of temperature.

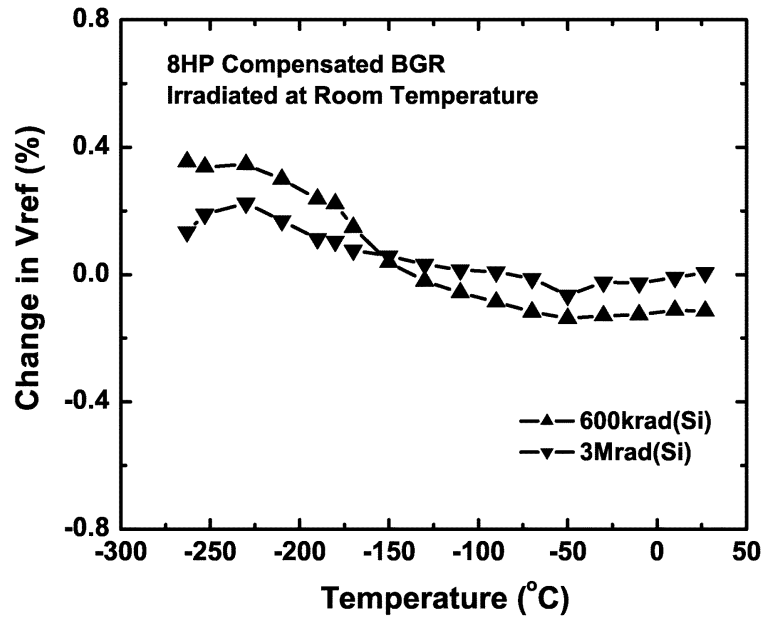

Fig. 11. Change in the output voltage of curvature-compensated 8HP BGR irradiated at room temperature as a function of temperature.

two branches can degrade the overall performance of the circuit and measurement results confirms this assumption. Figs. 8 and 9 show the measured output voltage of the 5AM BGR as a function of power supply at three different temperatures for total doses of $600 \mathrm{krad}(\mathrm{Si})$ and $3 \mathrm{Mrad}(\mathrm{Si})$, respectively. It can be seen that the line regulation remains well-behaved across the extreme temperature range both before and after irradiation, clearly good news.

Figs. 10 and 11 show the percentage change in the output voltages of the $8 \mathrm{HP}$ first-order and curvature-compensated BGRs, respectively, for total dose values of $600 \mathrm{krad}(\mathrm{Si})$ and $3 \mathrm{Mrad}(\mathrm{Si})$. From these data, it can be seen that the circuits function well down to temperatures as low as $-263^{\circ} \mathrm{C}$. It can be observed that the proton-induced changes in the BGR are minor, even at cryogenic temperatures. Comparing the effects of proton radiation on the circuits for the two $\mathrm{SiGe}$ technologies, we can see that $5 \mathrm{AM}$ references are generally more susceptible to radiation damage than $8 \mathrm{HP}$ references, consistent with the overall TID robustness of the individual transistors [4]. 


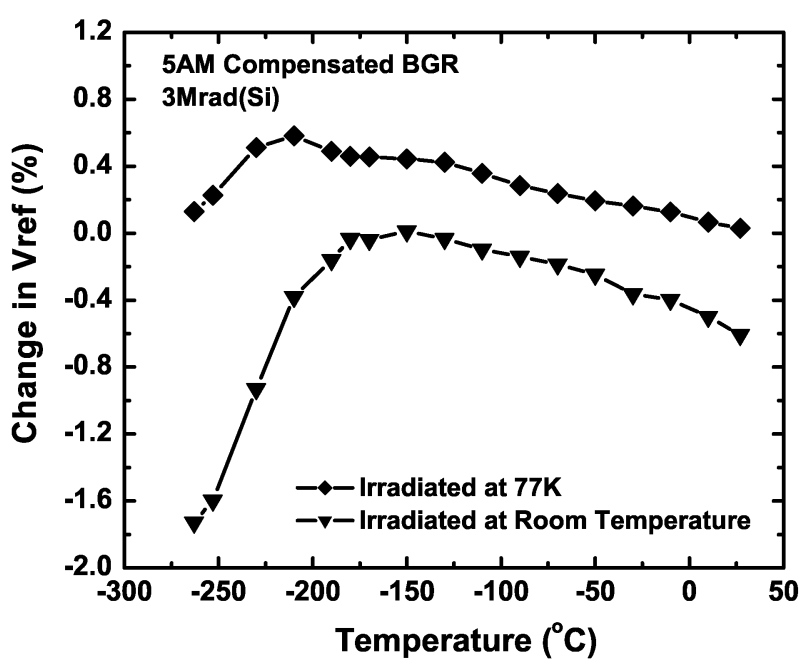

Fig. 12. Change in the output voltage of $5 \mathrm{AM}$ BGR irradiated at $77 \mathrm{~K}$ as a function of temperature.

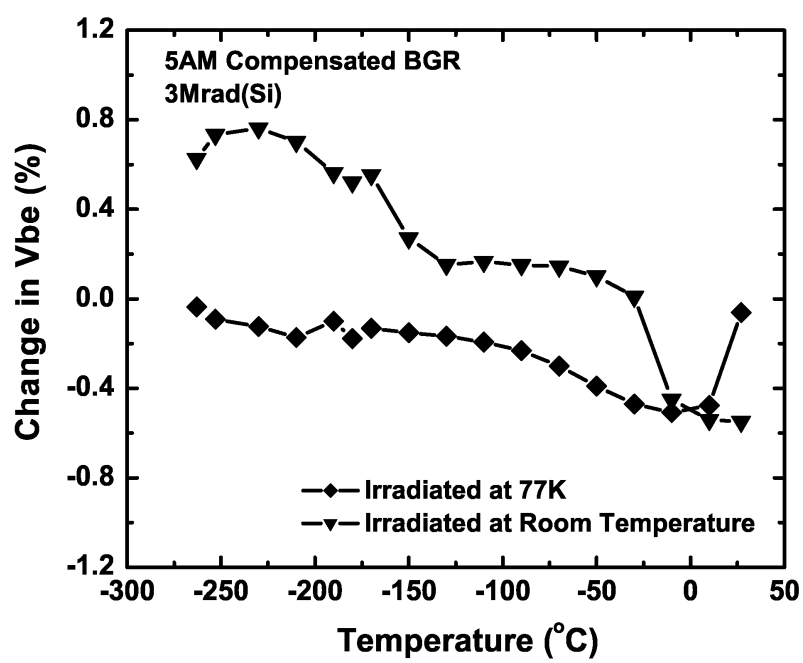

Fig. 13. Change in the base-emitter voltage of $Q_{3}$ inside 5AM BGR irradiated at $77 \mathrm{~K}$ as a function of temperature.

\section{B. Experiment II}

In this experiment, the effects of proton irradiation on the voltage references implemented in both $\mathrm{SiGe}$ technologies were investigated when irradiated cold. The samples were irradiated at $77 \mathrm{~K}$ and under operational bias during the experiment. Measurement results are shown in Figs. 12-18. In each figure, result from the radiation performed at room temperature is also shown for comparison. The percentage change in the output voltage of the 5AM BGR is shown in Fig. 12. It can be observed that the change in the output voltage when the reference is irradiated cold is much less than when it is irradiated at room temperature, clearly good news for applications at cryogenic temperatures. This is consistent with what was observed for the individual transistors [16]. Fig. 13 shows that the percentage change in the base-emitter voltage of transistor $Q_{3}$ is less than $0.5 \%$ when the reference is irradiated at $77 \mathrm{~K}$. The percentage change in the base-emitter voltage difference of transistors $Q_{1}$ and $Q_{2}$ is shown in Fig. 14. It can be seen that for most temperatures

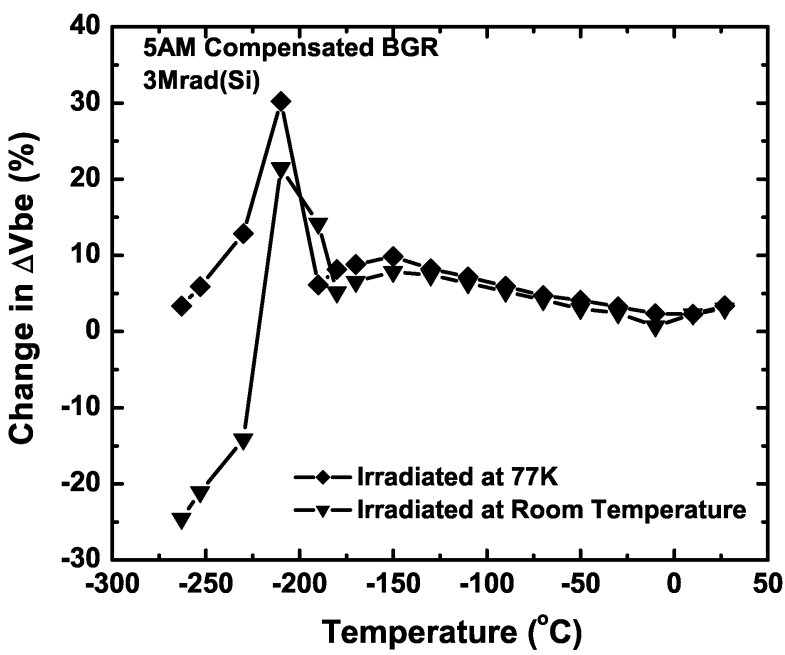

Fig. 14. Change in the difference of $Q_{1}$ and $Q_{2}$ base-emitter voltages of 5AM $\mathrm{BGR}$ irradiated at $77 \mathrm{~K}$ as a function of temperature.

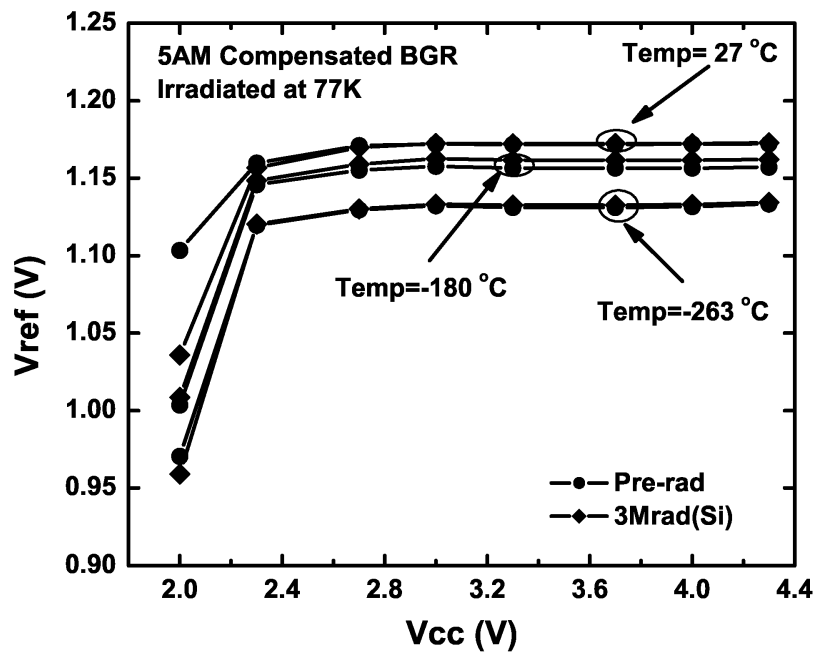

Fig. 15. Output voltage of the 5AM BGR as a function of power supply at $27^{\circ} \mathrm{C},-180^{\circ} \mathrm{C}$ and $-263^{\circ} \mathrm{C}$-irradiated at $77 \mathrm{~K}$.

the percentage change remains the same for both samples (irradiated at room temperature and irradiated at $77 \mathrm{~K}$ ). Interestingly, however, at deep cryogenic temperatures, the percentage change in $\Delta V_{\text {be }}$ for the sample irradiated at room temperature is far larger than that of the sample irradiated cold. Fig. 15 shows the output voltage of the 5AM BGR irradiated at $77 \mathrm{~K}$ as a function of the power supply at three temperatures. Line regulation remains well-behaved after proton radiation at $77 \mathrm{~K}$.

The percentage change of the output voltages of the 8HP references as a function of total dose at $77 \mathrm{~K}$ are plotted in Fig. 16. As can be seen, the percentage change increases as the total dose increases. The change in the output voltage of the first-order and curvature-compensated 8HP BGRs irradiated at $77 \mathrm{~K}$ as a function of temperature are shown in Figs. 17 and Figs. 18, respectively. Unlike the case of the 5AM references, the output voltage of the 8HP samples irradiated at $77 \mathrm{~K}$ changed more after irradiation compared with the samples irradiated at room temperature. However, the percentage change for both $8 \mathrm{HP}$ references is less than $0.4 \%$, clearly acceptable for most applications. 


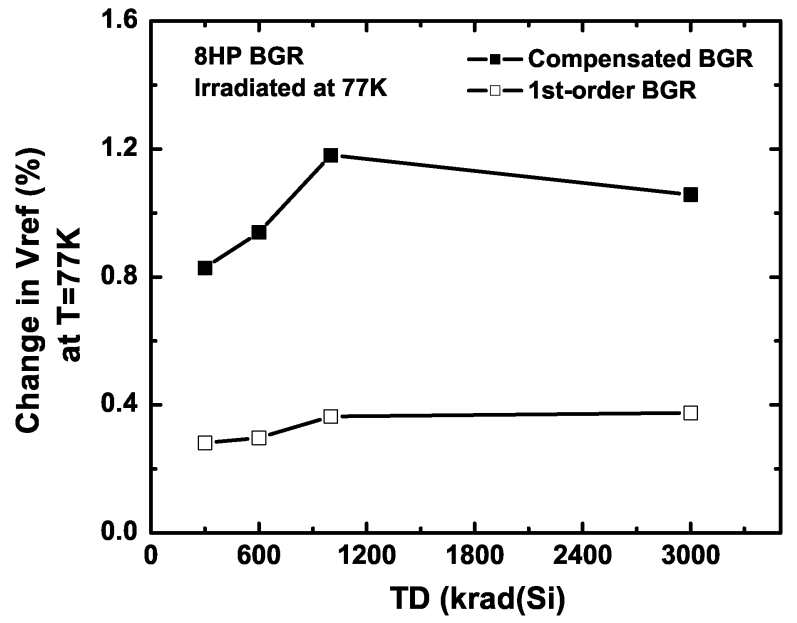

Fig. 16. Output voltage of $8 \mathrm{HP}$ references as a function of total dose for $77 \mathrm{~K}$ irradiation.

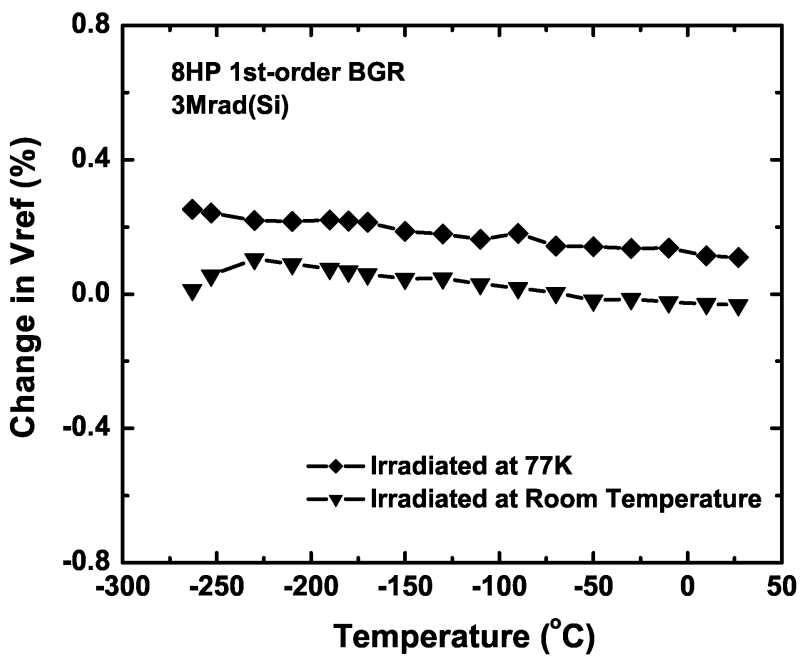

Fig. 17. Change in the output voltage of the first-order 8HP BGR irradiated at $77 \mathrm{~K}$ as a function of temperature.

\section{Experiment III}

In this experiment, the 8HP curvature-compensated reference was irradiated at room temperature with all the pins grounded. Measurement results of this experiment are shown in Fig. 19. Data obtained from experiment I is also shown for comparison. Interestingly, these results indicate the proton damage for this reference is larger for the case when the circuit is under bias during radiation, compared to the case when the circuit is irradiated with all pins grounded.

The temperature coefficients of the 5AM voltage reference both before and after irradiation from the two experiments, across four different temperature ranges, are summarized in Table. I. These numbers demonstrate that the impact of proton irradiation at $77 \mathrm{~K}$ on the output voltages and temperature coefficients of the 5AM BGR circuit are minor, and are clearly encouraging for extreme environment applications of SiGe technology.

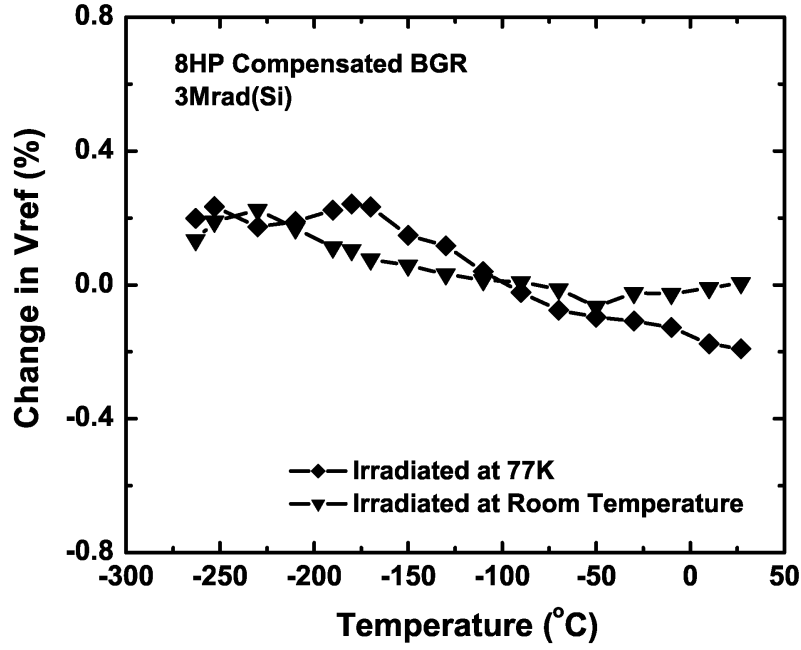

Fig. 18. Change in the output voltage of curvature-compensated 8HP BGR irradiated at $77 \mathrm{~K}$ as a function of temperature.

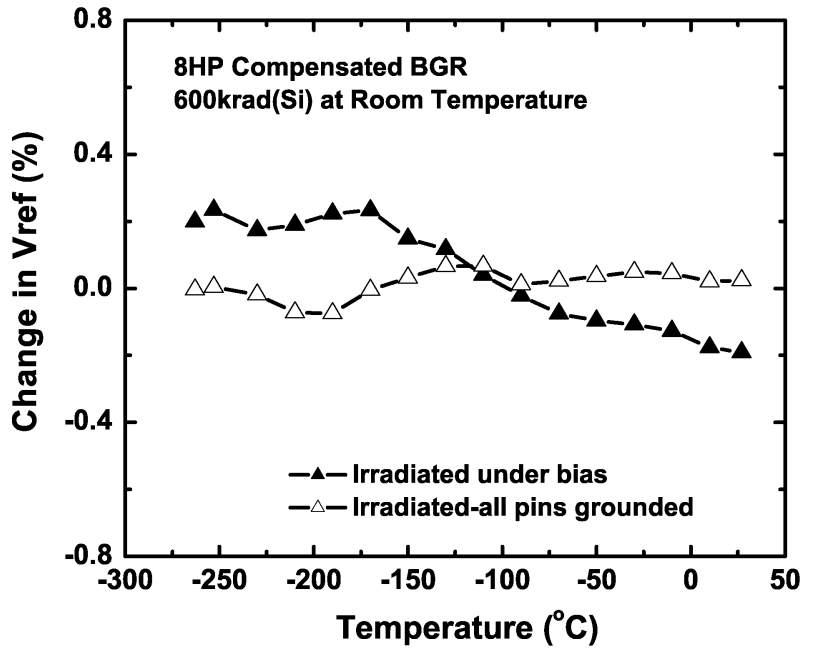

Fig. 19. Change in the output voltage of curvature compensated 8HP BGR irradiated with all pins grounded, as a function of temperature.

\section{SUMMARY}

In this paper the proton tolerance of SiGe BiCMOS voltage references intended for extreme temperature range electronics was investigated. The reference circuits were designed in two distinct SiGe technologies (IBM SiGe 5AM and IBM SiGe 8HP). Three separate proton radiation experiments were performed. Measurement results show that the PTAT current generator inside the reference circuits is the most vulnerable component of the circuits to induced proton damage, but in general the circuits work well up to Mrad levels of total dose. The output voltage of the 5AM reference circuits show larger percentage changes than that those of the $8 \mathrm{HP}$ references, after irradiation at room temperature. Irradiation at $77 \mathrm{~K}$ produces less damage to the 5AM reference circuits than irradiation at room temperature. For the 8HP reference circuits, the damage of radiation at $77 \mathrm{~K}$ was slightly larger than the damage of radiation at room temperature, but still relatively minor. Comparing the measurement results at $27^{\circ} \mathrm{C}$ obtained from this study 
TABLE I

Temperature Coefficients of 5AM Sige Voltage ReFerence OVER DifFerent TeMPerature Ranges

\begin{tabular}{|c||c|c||r|c|}
\hline \multicolumn{1}{|c||}{ Temperature Range } & \multicolumn{2}{|c||}{ Experiment I } & \multicolumn{2}{c|}{ Experiment II } \\
\cline { 2 - 5 } & pre-rad & post-rad $(3 \mathrm{Mrad}(\mathrm{Si}))$ & pre-rad & post-rad \\
\hline \hline$(-55 \text { to } 27)^{\circ} \mathrm{C}$ & $19.52 \mathrm{ppm} /{ }^{\circ} \mathrm{C}$ & $27.45 \mathrm{ppm} /{ }^{\circ} \mathrm{C}$ & $8.06 \mathrm{ppm} /{ }^{\circ} \mathrm{C}$ & $19.22 \mathrm{ppm} /{ }^{\circ} \mathrm{C}$ \\
\hline$(-180 \text { to } 27)^{\circ} \mathrm{C}$ & $72.29 \mathrm{ppm} /{ }^{\circ} \mathrm{C}$ & $55.11 \mathrm{ppm} /{ }^{\circ} \mathrm{C}$ & $64.61 \mathrm{ppm} /{ }^{\circ} \mathrm{C}$ & $49.99 \mathrm{ppm} /{ }^{\circ} \mathrm{C}$ \\
\hline$(-243 \text { to } 27)^{\circ} \mathrm{C}$ & $96.29 \mathrm{ppm} /{ }^{\circ} \mathrm{C}$ & $168.83 \mathrm{ppm} /{ }^{\circ} \mathrm{C}$ & $101.66 \mathrm{ppm} /{ }^{\circ} \mathrm{C}$ & $88.08 \mathrm{ppm} /{ }^{\circ} \mathrm{C}$ \\
\hline$(-263 \text { to } 27)^{\circ} \mathrm{C}$ & $122.37 \mathrm{ppm} /{ }^{\circ} \mathrm{C}$ & $167.51 \mathrm{ppm} /{ }^{\circ} \mathrm{C}$ & $120.63 \mathrm{ppm} /{ }^{\circ} \mathrm{C}$ & $121.52 \mathrm{ppm} /{ }^{\circ} \mathrm{C}$ \\
\hline
\end{tabular}

with those of previous studies [5]-[7] indicates that the output voltage change due to proton influence is minimal in these $\mathrm{SiGe}$ circuits, even down to cryogenic temperatures, demonstrating the utility of SiGe technology for emerging space exploration applications.

\section{ACKNOWLEDGMENT}

The authors would like to thank K. LaBel, L. Cohn, M. Mojarradi, E. Kolawa, M. Watson, D. Frazier, and the SiGe team at IBM for their contributions and support of this work.

\section{REFERENCES}

[1] J. D. Cressler and G. Niu, Silicon-Germanium Heterojunction Bipolar Transistors, 1st ed. Norwood, MA: Artech House, 2003.

[2] C.-W. Tseng, E. J. Mccluskey, X. Shao, and D. M. Wu, "Cold delay defect screening," in Proc. IEEE VLSI Test Symp., May 2000, pp. 183-188.

[3] J. D. Cressler, R. Krithivasan, G. Zhang, G. Niu, P. W. Marshall, H. S. Kim, R. A. Reed, M. J. Palmer, and A. J. Joseph, "An investigation of the origins of the variable proton tolerance in multiple SiGe HBT BiCMOS technology generations," IEEE Trans. Nucl. Sci., vol. 49, no. 6, pp. 3203-3207, Dec. 2002.

[4] Y. Lu, J. D. Cressler, R. Krithivasan, Y. Li, R. A. Reed, P. W. Marshall, C. Polar, G. Freeman, and D. Ahlgren, "Proton tolerance of third-generation, $0.12 \mu \mathrm{m} 185 \mathrm{GHz}$ SiGe HBTs," IEEE Trans. Nucl. Sci., vol. 50, no. 6, pp. 1811-1815, Dec. 2003.

[5] B. G. Rax, C. I. Lee, and A. H. Johnston, "Degradation of precision reference devices in space environments," IEEE Trans. Nucl. Sci., vol. 44, no. 6, pp. 1939-1944, Dec. 1997.

[6] S. S. McClure, J. L. Gorelick, R. L. Pease, B. G. Rax, and R. L. Ladbury, "Total dose performance of radiation hardened voltage regulators and references," in Proc. IEEE Radiation Data Workshop, Vancouver,, BC, Canada, Jul. 2001, pp. 1-5.

[7] M. V. O'Bryan, K. A. LaBel, R. A. Reed, J. W. J. Howard, R. L. Ladbury, J. L. Barth, S. D. Kniffin, C. M. Seidleck, P. W. Marshall, C. J. Marshall, H. S. Kim, D. K. Hawkins, A. B. Sanders, M. A. Carts, J. D. Forney, D. R. Roth, J. D. Kinnison, E. Nhan, and K. Sahu, "Radiation damage and single event effect results for candidate spacecraft electronics," in Proc. IEEE Radiation Data Workshop, Reno, NV, Jul. 2000, pp. 106-122.
[8] J. D. Cressler, M. C. Hamilton, R. Krithivasan, H. Ainspan, R. Groves, G. Niu, S. Zhang, Z. Jin, C. J. Marshall, P. W. Marshall, H. S. Kim, R. A. Reed, M. J. Palmer, A. J. Joseph, and D. L. Harame, "Proton radiation response of SiGe HBT analog and RF circuits and passives," IEEE Trans. Nucl. Sci., vol. 48, no. 6, pp. 2238-2243, Dec. 2001.

[9] I. Lee, G. Kim, and W. Kim, "Exponential curvature-compensated BiCMOS bandgap references," IEEE J. Solid-State Circuits, vol. 29, pp. 1396-1403, Nov. 1994.

[10] J. M. Roldan, G. Niu, W. E. Ansley, J. D. Cressler, S. D. Clark, and D. C. Ahlgren, "An investigation of the spatial location of proton-induced traps in SiGe HBTs," IEEE Trans. Nucl. Sci., vol. 45, no. 6, pp. 2424-2429, Dec. 2003.

[11] B. Jagannathan, M. Khater, F. Pagette, J.-S. Rieh, D. Angell, H. Chen, J. Florkey, F. Golan, D. R. Greenberg, R. Groves, S. J. Jeng, J. Johnson, E. Mengistu, K. T. Schonenberg, C. M. Schnabel, P. Smith, A. Stricker, D. Ahlgren, G. Freeman, K. Stein, and S. Subbanna, "Self-aligned SiGe NPN transistors with $285 \mathrm{GHz} f_{M A X}$ and $207 \mathrm{GHz} f_{T}$ in a manufacturable technology," IEEE Electron Device Lett., vol. 23, pp. 258-260, May 2002.

[12] B. Banerjee, S. Venkataraman, Y. Lu, Q. Liang, C.-H. Lee, S. Nuttinck, D. Heo, Y.-J. Chen, J. D. Cressler, J. Laskar, G. Freeman, and D. Ahlgren, "Cryogenic operation of third-generation, 200-GHz peak$f_{T}$, silicon-germanium heterojunction bipolar transistors," IEEE Trans. Elec. Dev., vol. 52, no. 2, pp. 585-593, Apr. 2005.

[13] P. R. Gray and R. G. Meyer, Analysis and Design of Analog Integrated Circuits, 4th ed. New York: Wiley, 2001.

[14] P. W. Marshall, C. J. Dale, M. A. Carts, and K. A. LaBel, "Particleinduced bit errors in high performance fiber optic data links for satellite data management," IEEE Trans. Nucl. Sci., vol. 41, no. 6, pp. 1958-1965, Dec. 1994.

[15] C. M. Grens, B. M. Haugerud, A. K. Sutton, T. Chen, J. D. Cressler, P. W. Marshall, C. J. Marshall, and A. J. Joseph, "The effects of proton irradiation on the operating voltage constraints of SiGe HBTs," IEEE Trans. Nucl. Sci., vol. 52, no. 6, pp. 2403-2407, Dec. 2005.

[16] A. P. G. Prakash, A. Sutton, R. Diestelhorst, G. Espinel, J. Andrews, B. Jun, J. D. Cressler, and C. J. Marshall, "The effect of irradiation temperature on the proton response of SiGe HBTs," IEEE Trans. Nucl. Sci., submitted for publication. 